Сергій Ататолійович Микусь (кандидат військових наук, доцент) ${ }^{1}$

Олена Михайлівна Сівоха ${ }^{2}$

Ростислав Валерійович Лісневський (кандидат технічних наук, доцент) ${ }^{3}$

${ }^{1}$ Національний університет оборони Украӥни імені Івана Черняховського, Київ, Украйна

${ }^{2}$ Військовий інститут телекомунікації та інформатизації, Київ, Украӥна

${ }^{3}$ Кийвський національний університет імені Тараса Шевченка, Київ, Украӥна

\title{
ПІДХОДИ ДО ВИБОРУ ВАРІАНТУ ПОБУДОВИ ІНФОРМАЦІЙНО- ТЕЛЕКОМУНІКАЦІЙНОЇ СИСТЕМИ ВІЙСЬКОВОГО ПРИЗНАЧЕННЯ
}

В теперішній час, найбільший актуальними залишаються питання оцінки ІТСВП при виборі варіанту побудови ІТСВП на етапі планування зв'язку. Оиінка ІТС не є самоиіллю, а є основою для кількісного обтрунтування рішення на організацію зв'язку. Це $і$ обумовлює актуальність проблеми вибору варіанту побудови інформаційно-телекомунікаційної системи військового призначення.

Складні системи (до яких відноситься також і система зв'язку), перебуваючи в різних умовах (ситуаціях, режимах), виявляють різні системні властивості, в тому числі і не сумісні ні з однією 3 ситуацій окремо. Однак жодною не можна нехтувати, оскільки кожна характеризує якусь властивість досліджуваного явища, i жодна з них не може бути прийнята як єдина, оскільки не виражає всіх його властивостей. Розробка формального апарату рішення багато параметричних задач оцінки ефективності функціонування системи зв'язку передбачає системний взаємозв'язок суперечливих показників.

Виходячи з изього, пропонується удосконалена методики вибору варіанту побудови інформаційнотелекомунікаційної системи військового призначення, яка відрізняється від існуючої тим, щчо особа, щчо приймає рішення на організацію зв'язку, з визначених можливих варіантів обирає раціональний за рахунок використання методів аналізу ієрархій і таксономії.

Ключові слова: інформаційно-телекомунікаційна система військового призначення; вибір варіанту побудови інформаційно-телекомунікаційної системи військового призначення; показники оиінки.

\begin{abstract}
Вступ
Постановка проблеми. Інформаційнотелекомунікаційна система військового призначення (ІТСВП) - частина системи військового зв'язку, що являє собою сукупність військових телекомунікаційних мереж доступу та військової транспортної телекомунікаційної мережі і призначена для забезпечення службових осіб органів військового управління телекомунікаційними послугами та надання каналів передавання і групових трактів засобам та комплексам автоматизації [1-2].

Тому вона повинна відповідати вимогам, які ставляться до неї вищою системою, тобто системою управління військами щодо забезпечення управління. Це вимагає оцінки рівня iii пристосування до виконання поставлених перед нею завдань, або ж ступеню іiі відповідності своєму цільовому призначенню.

Оцінка ІTC не є самоціллю, а є основою для кількісного обгрунтування рішення на організацію зв'язку. При цьому основними задачами можуть бути наступні: вибір варіанта побудови ІТСВП на етапі іiі проектування; вибір варіанта побудови ІТСВП на етапі планування зв'язку; вибір варіанту нарощування ITC в динаміці бойових дій; вибір доцільних способів організації зв'язку; визначення ефективності діючої ІТСВП. В теперішній час,
\end{abstract}

найбільший актуальними залишаються питання оцінки ІТСВП при вирішенні другої задачі.

Аналіз остатніх досліджень і публікацій. Проблематиці оцінки телекомунікаційних систем приділяють увагу багато вчених, як в Україні, так і за кордоном. Деякі досліджують питання: в статті [3] - проектування сучасних систем управління телекомунікація ми, як складних технічних систем (Дищук А. С.); в статті [4] - визначення комплексного ймовірнісного показника ефективності діяльності на основі моделювання телекомунікаційної мережі та використання математичного апарату нечітких чисел (Басараб K.O.).

В статті [5] розглянуто різні підходи до вибору показників, які використовуються для оцінки ефективності функціонування системи зв'язку, обгрунтовано використання для оцінки ефективності системи зв'язку узагальненого показника шляхом нормування значень часткових показників та їх складування, але не враховано важливість кожного показника.

В роботі [6] розглянуто запропонований показник ефективності мереж зв'язку та їх елементів, що забезпечує можливість їх порівняння на етапах створення та експлуатації та наведено метод визначення показника ефективності і оптимальної робочої точки функціонування мережі зв'язку та їі елементів, але

(C) С.А.Микусь, О.М.Сівоха, Р.В.Лісневський

Modern Information Technologies in the Sphere of Security and Defence № 2(38)/2020 ISSN2311-7249(Print)/ISSN2410-7336(Online) 
не вирішено питання визначення комплексного показника оцінки варінтів побудови ITC на етапі планування.

Проведений аналіз дозволяє зробити висновок про те, що розглянуті підходи в оцінці ITC в не повній мірі відповідають вимогам, що накладаються на сучасні ITC

Таким чином, метою статті є визначення підходів до вибору варіантів побудови ІТСВП на етапі планування зв'язку.

\section{Виклад основного матеріалу дослідження}

Сучасна наука для вивчення складних явищ i об'єктів застосовує системний підхід. Комплексний об’єкт дослідження не може характеризуватися якоюсь однією (найбільш важливою або типовою) ознакою, при його описі одночасно враховуються велика кількість нероздільних властивостей. Навіть якщо досліджується не весь комплексний об'єкт, а лише його частина, сучасний системний підхід вимагає залучення всього спектра властивостей. Будь-який фрагмент комплексу доводиться розглядати не ізольовано, а в багато численних суперечливих взаємозв'язках i, що важливо, в різних можливих ситуаціях [7]. Складні системи (до яких відноситься також і система зв'язку), перебуваючи в різних умовах (ситуаціях, режимах), виявляють різні системні властивості, в тому числі і не сумісні ні 3 однією 3 ситуацій окремо. При їх вивченні застосовується підхід, що складається в створенні і одночасному співіснуванні не однієї, а багатьох теоретичних моделей одного і того ж явища, причому деякі 3 них концептуально суперечать один одному [7]. Однак жодною не можна нехтувати, оскільки кожна характеризує якусь властивість досліджуваного явища, i жодна 3 них не може бути прийнята як єдина, оскільки не виражає всіх його властивостей. Розробка формального апарату рішення багато параметричних задач оцінки ефективності функціонування системи зв'язку передбачає системний взаємозв'язок суперечливих показників.

Виходячи 3 цього, автором пропонується удосконалена методики вибору варіанту побудови інформаційно-телекомунікаційної системи військового призначення, структурна схема якої наведена на рис. 1. Вона включає дванадцять блоків і має три складові:

I - вибір показників та визначення коефіцієнтів їх важливості (блок 1);

II - визначення можливих варіантів побудови ІТСВП та розрахунок значень показників (розрахунки та методики, які становлять блоки 2, 3);

III - порівняльний аналіз варіантів побудови ІТСВП та вибір оптимального (таксономічний метод, блоки 4-12).

Визначення оптимального варіанту побудови ІТСВП здійснюється в наступній послідовності:

1. Постановка задачі, яка полягає у виборі показників оцінки ІТСВП $\left(\mathrm{W}_{\mathrm{j}}\right)$ i визначенні коефіцієнтів їх важливості $\left(\lambda_{\mathrm{j}}\right)$ за допомогою методу аналізу ієрархій.

2. Визначення можливих варіантів структури побудови ІТСВП і способів організації зв'язку.

3. Розрахунок значень показників для всіх варіантів побудови ІТСВП здійснюється за допомогою методик та відповідних розрахунків [3, 7]. При цьому здійснюється оцінка ІТСВП, яка планується до розгортання, для кожного 3 визначених в другому блоці варіантів по обраним показникам ( $\left.\mathrm{W}_{\mathrm{j}}\right)$.

4. Створення матриці значень розрахованих показників оцінки ІТСВП.

Значення розрахованих в третьому блоці методики показників $\left[\mathrm{w}_{\mathrm{ij}}\right], \mathrm{i}=\overline{1, \mathrm{~N}}, \mathrm{j}=\overline{\mathrm{1}, \mathrm{R}}$ зводяться в матрицю, загальний вигляд якої зображений на рис. 2.

5. Приведення значень показників до стандартизованого вигляду. Значення розрахованих показників оцінки ІТСВП мають різні одиниці вимірювання, тому для полегшення обчислювань доцільно їх привести до стандартизованого вигляду за формулою: $\mathrm{Z}_{\mathrm{ij}}=\frac{\mathrm{W}_{\mathrm{ij}}-\mathrm{W}_{\mathrm{j}}}{\mathrm{S}_{\mathrm{j}}}$,

де $\mathrm{w}_{\mathrm{j}}=\frac{1}{\mathrm{~N}} \sum_{\mathrm{i}} \mathrm{w}_{\mathrm{ij}}, \mathrm{i}=\overline{1, \mathrm{~N}}$ для $\mathrm{N}$ варіантів;

$\mathrm{S}_{\mathrm{j}}=\left[\frac{1}{\mathrm{~N}-1} \sum_{\mathrm{i}}\left(\mathrm{w}_{\mathrm{ij}}-\mathrm{w}_{\mathrm{j}}\right)^{2}\right]^{\frac{1}{2}}$;

$\mathrm{w}_{\mathrm{j}}$ - середнє арифметичне значення $\mathrm{j}$-го показника по варіантах;

$\mathrm{S}_{\mathrm{j}}$ - середнє квадратичне відхилення $\mathrm{j}$-го показника;

$Z_{\mathrm{ij}}$ - стандартизоване значення $\mathrm{j}$-го показника ефективності функціонування для i -го варіанту.

6. Вибір оптимального варіанту. У блоці 6 здійснюється вибір оптимального варіанту побудови ITC в операції 3 урахуванням коефіцієнтів важливості $\left(\lambda_{\mathrm{j}}\right)$ показників оцінки ІТСВП за формулою: $\mathrm{S}\left(\mathrm{A}_{\mathrm{i}}\right)=\sum_{\mathrm{i}} \mathrm{Z}_{\mathrm{ij}} \lambda_{\mathrm{j}}$.

Чим більше значення $\mathrm{S}\left(\mathrm{A}_{\mathrm{i}}\right)$, тим краще варіант, що досліджується. Якщо один з варіантів побудови ІТСВП має суттєву перевагу відносно інших, то приймається рішення (блок 12) про його вибір, як оптимального. Якщо певна кількість варіантів мають однакові значення $\mathrm{S}\left(\mathrm{A}_{\mathrm{i}}\right)$ або перевага не суттєва, тобто вибір раціонального варіанту не можливий, здійснюється порівняльний аналіз варіантів побудови ІТСВП за допомогою таксономічних методів (блоки 7-11 удосконаленої методики). 
Military cybernetics and system analysis

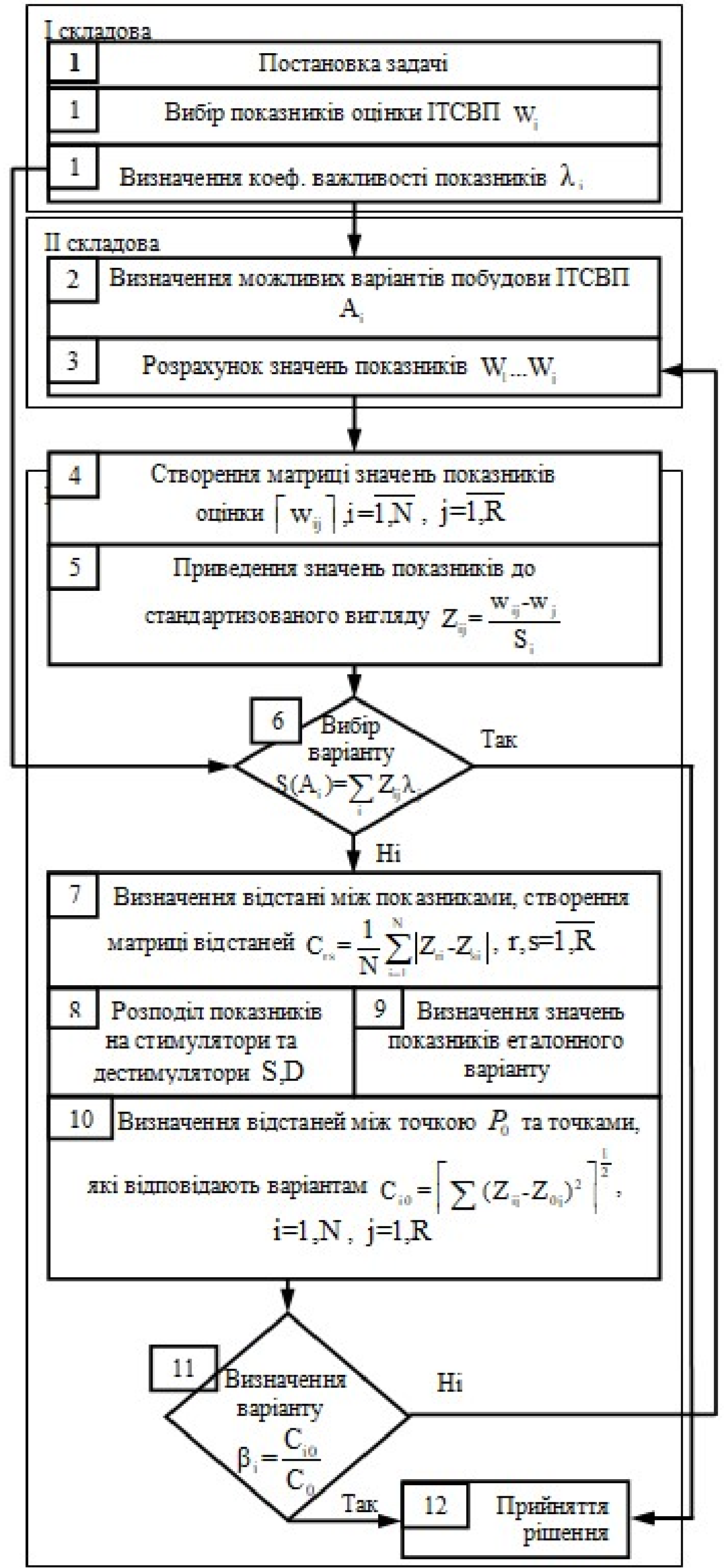

Рис. 1. Структурна схема удосконаленої методики вибору варіанту побудови інформаційнотелекомунікаційної системи військового призначення. 


\begin{tabular}{|c|c|c|c|c|c|c|}
\hline \multirow{2}{*}{$\begin{array}{c}\text { № } \\
\text { варіанта }\end{array}$} & \multicolumn{6}{|c|}{ Показники ефективності } \\
\hline & $\mathrm{W}_{1}$ & $\mathrm{~W}_{2}$ & $\cdots$ & $\mathrm{W}_{\mathrm{j}}$ & $\ldots$ & $\mathrm{W}_{\mathrm{r}}$ \\
\hline $\mathrm{A}_{1}$ & $w_{11}$ & $w_{12}$ & $\cdots$ & $w_{1 j}$ & $\cdots$ & $w_{1 r}$ \\
\hline $\mathrm{A}_{2}$ & $w_{21}$ & $w_{22}$ & $\ldots$ & $w_{2 j}$ & $\ldots$ & $w_{2 r}$ \\
\hline . & . & . & $\ldots$ & . & $\ldots$ & . \\
\hline . & . & . & $\cdots$ & . & $\ldots$ & . \\
\hline . & . & . & $\ldots$ & . & $\ldots$ & . \\
\hline $\mathrm{A}_{\mathrm{i}}$ & $w_{j 1}$ & $w_{j 2}$ & $\ldots$ & $w_{i j}$ & $\cdots$ & $w_{i r}$ \\
\hline$\cdot$ & ${ }^{\circ}$ & $\cdot$ & $\cdots$ & . & $\cdots$ & . \\
\hline . & . & . & $\cdots$ & . & $\ldots$ & . \\
\hline . & . & $\cdot$ & $\cdots$ & . & $\cdots$ & . \\
\hline$A_{n}$ & $w_{n 1}$ & $w_{n 2}$ & $\ldots$ & $w_{n j}$ & $\ldots$ & $w_{n r}$ \\
\hline
\end{tabular}

Рис. 2. Загальний вигляд матриці значень розрахованих показників оцінки ІТСВП.

7. Визначення відстані між показниками. Після стандартизації визначаються елементи матриці відстаней між показниками. Для цього використовується середня абсолютна різниця їх значень (середне по модулю за всіма варіантами), яка визначається за формулою [8]

$$
\mathrm{C}_{\mathrm{rs}}=\frac{1}{\mathrm{~N}} \sum_{\mathrm{i}=1}^{\mathrm{N}}\left|\mathrm{Z}_{\mathrm{ri}}-\mathrm{Z}_{\mathrm{si}}\right|, \mathrm{r}, \mathrm{s}=\overline{1, \mathrm{R}} \text {. }
$$

Створюється матриця відстаней, загальний вигляд якої зображений на рис. 3 .

\begin{tabular}{|c|c|c|c|c|c|c|c|c|}
\hline Показники & 1 & 2 & $\ldots$ & $\mathrm{S}$ & $\ldots$ & R-2 & R-1 & $\mathrm{R}$ \\
\hline 1 & 0 & $\mathrm{C}_{12}$ & $\ldots$ & $\mathrm{C}_{1 \mathrm{~S}}$ & $\ldots$ & $\mathrm{C}_{1(\mathrm{R}-2)}$ & $\mathrm{C}_{1(\mathrm{R}-1)}$ & $\mathrm{C}_{1 \mathrm{R}}$ \\
\hline 2 & $\mathrm{C}_{21}$ & 0 & $\ldots$ & $\mathrm{C}_{2 \mathrm{~S}}$ & $\ldots$ & $\mathrm{C}_{2(\mathrm{R}-2)}$ & $\mathrm{C}_{2(\mathrm{R}-1)}$ & $\mathrm{C}_{2 \mathrm{R}}$ \\
\hline$\ldots$ & $\ldots$ & $\ldots$ & 0 & $\ldots$ & $\ldots$ & $\ldots$ & $\ldots$ & $\ldots$ \\
\hline$r$ & $\mathrm{C}_{\mathrm{r} 1}$ & $C_{r 2}$ & $\ldots$ & 0 & $\ldots$ & $\mathrm{C}_{\mathrm{r}(\mathrm{R}-2)}$ & $\mathrm{C}_{\mathrm{r}(\mathrm{R}-1)}$ & $\mathrm{C}_{\mathrm{rR}}$ \\
\hline ... & $\cdots$ & $\ldots$ & $\ldots$ & $\ldots$ & 0 & $\ldots$ & $\ldots$ & $\ldots$ \\
\hline $\mathrm{R}-2$ & $\mathrm{C}_{(\mathrm{R}-2) 1}$ & $\mathrm{C}_{(\mathrm{R}-2) 2}$ & $\ldots$ & $\mathrm{C}_{(\mathrm{R}-2) \mathrm{S}}$ & $\ldots$ & 0 & $\mathrm{C}_{(\mathrm{R}-2)(\mathrm{R}-1)}$ & $\mathrm{C}_{(\mathrm{R}-2) \mathrm{R}}$ \\
\hline $\mathrm{R}-1$ & $\mathrm{C}_{(\mathrm{R}-1) 1}$ & $\mathrm{C}_{(\mathrm{R}-1) 2}$ & $\cdots$ & $\mathrm{C}_{(\mathrm{R}-1) \mathrm{S}}$ & $\cdots$ & $\mathrm{C}_{(\mathrm{R}-1)(\mathrm{R}-2)}$ & 0 & $\mathrm{C}_{(\mathrm{R}-1) \mathrm{R}}$ \\
\hline $\mathrm{R}$ & $\mathrm{C}_{\mathrm{R} 1}$ & $\mathrm{C}_{\mathrm{R} 2}$ & $\ldots$ & $\mathrm{C}_{\mathrm{RS}}$ & $\ldots$ & $\mathrm{C}_{\mathrm{R}(\mathrm{R}-2)}$ & $\mathrm{C}_{\mathrm{R}(\mathrm{R}-1)}$ & 0 \\
\hline
\end{tabular}

Рис. 3. Матриця відстаней.

8. Розподіл показників на стимулятори та дестимулятори ( S,D ). Вибираються показники, збільшення значень яких призводить до зростання ефективності функціонування ІТСВП, відносимо ïx до стимуляторів та навпаки, значення показників зростання яких спричиняе зменшення ефективності функціонування ІТСВП - до дестимуляторів.

9. Визначення значень показників еталонного варіанту побудови ІТСВП. У цьому блоці будується еталонний варіант показників ІТСВП, якому відповідає точка $\mathrm{P}_{0}$ в багатовимірному просторі 3 координатами (значеннями стандартизованих показників):

$$
\begin{aligned}
& \mathrm{Z}_{01}, \mathrm{Z}_{02}, \ldots, \mathrm{Z}_{0 \mathrm{j}}, \ldots, \mathrm{Z}_{0 \mathrm{R}}, \\
& \text { де }-\mathrm{Z}_{0 \mathrm{j}}=\max _{\mathrm{i}} \mathrm{Z}_{\mathrm{ij}}, \text { коли } \mathrm{j} \in \mathrm{S} ; \\
& \mathrm{Z}_{0 \mathrm{j}}=\max _{\mathrm{i}} \mathrm{Z}_{\mathrm{ij}}, \text { коли } \mathrm{j} \in \mathrm{D} ;
\end{aligned}
$$$$
\text { S,D - множини стимуляторів i }
$$
дестимуляторів відповідно; 
$\mathrm{Z}_{\mathrm{ij}}$ - стандартизоване значення $\mathrm{j}$-го показника для $\mathrm{i}$-го варіанту системи.

10. Визначення відстаней між точкою $\mathrm{P}_{0}$ та точками, які відповідають варіантам системи, визначаються за формулою

$$
\mathrm{C}_{\mathrm{i} 0}=\left[\sum_{\mathrm{j}}\left(\mathrm{Z}_{\mathrm{ij}}-\mathrm{Z}_{0 \mathrm{j}}\right)^{2}\right]^{\frac{1}{2}}, \mathrm{i}=\overline{1, \mathrm{~N}}, \mathrm{j}=\overline{1, \mathrm{R}} \text {. }
$$

11. Визначення оптимального варіанту побудови ІТСВП. Ступінь переваги варіантів визначається за формулою: $\beta_{\mathrm{i}}=\frac{\mathrm{C}_{\mathrm{i} 0}}{\mathrm{C}_{0}}$,

$$
\begin{gathered}
\text { де }-\mathrm{C}_{0}=\overline{\mathrm{C}_{0}}+2 \mathrm{~S}_{0} ; \overline{\mathrm{C}_{0}}=\frac{1}{\mathrm{~N}} \sum_{\mathrm{i}} \mathrm{C}_{\mathrm{i} 0}, \mathrm{i}=1, \mathrm{~N} ; \\
\mathrm{S}_{0}=\left[\frac{1}{\mathrm{~N}-1} \sum_{\mathrm{i}}\left(\mathrm{C}_{\mathrm{i} 0}-\overline{\mathrm{C}_{0}}\right)^{2}\right]^{\frac{1}{2}} .
\end{gathered}
$$

Чим ближче значення $\beta_{\mathrm{i}}$ до нуля, тим краще варіант, що досліджується. Якщо в результаті розрахунків отримуємо однакові значення $\beta_{\mathrm{i}}$ здійснюється коригування варіантів побудови ІТСВП.

\section{Лimepamypa}

1. ДСТУ В 3265-95 “Зв”язок військовий. Терміни та визначення". 2. Військовий стандарт 01.112.001 - 2006. “Військовий зв'язок. Терміни та визначення”. 3. Дищук А. С. Аналіз функціонування складного об'єкту системи управління в телекомунікаціях / А. С. Дишук // Телекомунікаційні та інформаційні технології.- 2016. №1. - С. 80-87. 4. Басараб О. К. Метод визначення комплексного ймовірнісного показника ефективності оперативно-службової діяльності Державної прикордонної служби України / О.К.Басараб // Наукоємні технології, 2013. № 3 (19) - С. 263-267. 5. Волошко С. В. Ефективність функціонування системи зв'язку і автоматизації та іiі вплив на ефективність управління військами (силами) / С. В. Волошко, М. О. Масесов // Сучасні інформаційні
12. Прийняття рішення. Обирається оптимальний варіант побудови ІТСВП.

\section{Висновки й перспективи подальших} досліджень

Таким чином, проведені розрахунки 3 використанням удосконаленої методики визначення оптимального варіанту побудови ІТСВП дозволяють особі, що приймає рішення на організацію зв'язку, 3 визначених можливих варіантів обрати раціональний за рахунок використання методів аналізу ієрархій і таксономіі. Тобто, під час використання удосконаленої методики отримано більш точні результати, при цьому оцінка ІТСВП, яка планується до розгортання, враховує коефіцієнти важливості обраних показників, що дозволяє начальнику зв'язку здійснити кількісне обгрунтування рішення із зв'язку, яке приймається.

Основні зусилля при проведенні подальших досліджень доцільно зосередити на: удосконаленні методик розрахунку показників оцінки ІТСВП; виборі та обгрунтуванні показників оцінки, які доцільно використовувати при виборі оптимального варіанту побудови ІТСВП; створенні програмного забезпечення для розрахунків показників оцінки ІТСВП, що планується.

технології у сфері безпеки та оборони. - 2011. - № 3 (12). - С. 9 - 12. 6. Карганов В.В. Показатель оценки эффективности систем связи и их элементов/ В.В. Карганов, А.Г. Расчесова, Кудряшов В.А. Научнотехнические ведомости Санкт-Петербургского государственного политехнического университета. Информатика. Телекоммуникации. Управление. - 2016. 7. Шевченко В. О. Системний підхід до розроблення методологічних основ дослідження телекомунікаційних мереж військового призначення / В. О. Шевченко // Наука і оборона. - 2004. - № 4. - С. 42-46. 8. Елементи дослідження складних систем військового призначення / Загорка O.M., Мосов С.П., Сбітнєв А.І., Стужук П.I. K.: HAOУ, 2005. - 100c.

\title{
ПОДХОДЫ К ВЫБОРУ ВАРИАНТОВ ПОСТРОЕНИЯ ИНФОРМАЦИОННО- ТЕЛЕКОММУНИКАЦИОННОЙ СИСТЕМЫ ВОЕННОГО НАЗНАЧЕНИЯ
}

\author{
Сергей Анатольевич Мыкусь (кандидат военных наук, доцент) ${ }^{1}$ \\ Елена Михайловна Сивохо ${ }^{2}$ \\ Ростислав Валерьевич Лисневский (кандидат технических наук, доцент) ${ }^{3}$
}

\author{
${ }^{1}$ Национальный университет обороны Украины имени Ивана Черняховского, Киев, Украина \\ ${ }^{2}$ Военный институт телекоммуникаций и информатизации имени Героев Крут, Киев, Украина \\ ${ }^{3}$ Киевский национальный университет имени Тараса Шевченка, Киев, Украина
}

В настоящее время, самый актуальными остаются вопросы оченки ИТСВП при выборе варианта построения ИТСВП на этапе планирования связи. Оценка ИТС не является самоцелью, а служит основой для количественного обоснования решения на организацию связи. Это и обусловливает актуальность проблемь выбора варианта построения информационно-телекоммуникационной системы военного назначения.

Сложные системы (к которым относится также и система связи), находясь в разных условиях (ситуациях, режимах), обнаруживают различные системные свойства, в том числе и не совместимые ни с одной из ситуаџий отдельно. Однако одной нельзя пренебрегать, поскольку каждая характеризует 
какое-то свойство изучаемого явления, и ни одна из них не может быть принята как единственная, поскольку не выражает всех его свойств. Разработка формального аппарата решения во параметрических задач оценки эффективности функционирования системы связи предусматривает системную взаимосвязь противоречивых показателей.

Исходя из этого, предлагается усовершенствованная методики выбора варианта построения информационно-телекоммуникационной системы военного назначения, отличается от существующей тем, что лицьо, принимающее решение на организацию связи, с определенных возможных вариантов выбирает рациональный за счет использования методов анализа иерархий и таксономии.

Ключевые слова: информационно-телекоммуникационная система военного назначения; выбор варианта построения информационно-телекоммуникационной системь военного назначения; показатели оценки.

\title{
APPROACHES TO THE SELECTION OF OPTIONS FOR BUILDING THE INFORMATION AND TELECOMMUNICATION SYSTEM FOR MILITARY PURPOSE
}

\author{
Serhii Mykus (Candidate of military sciences, associate professor) ${ }^{1}$ \\ Olena Sivokha ${ }^{2}$ \\ Rostyslav Lisnevskyi ${ }^{3}$ \\ ${ }^{1}$ National Defence University of Ukraine named after Ivan Cherniakhovsky, Kyiv, Ukraine \\ ${ }^{2}$ Military Institute of Telecommunications and Informatics named after Kruty Heroes, Kyiv, Ukraine \\ ${ }^{3}$ Taras Shevchenko National University of Kyiv, Kyiv, Ukraine
}

At the present time, the most relevant issues are the assessment of the ITSVP when choosing the option of building the ITSVP at the stage of communication planning. Evaluation of ITS is not an end in itself, but serves as the basis for a quantitative substantiation of the decision to organize communications. This determines the urgency of the problem of choosing an option for building a military information and telecommunications system.

Complex systems (which also include the communication system), being in different conditions (situations, modes), reveal different system properties, including those incompatible with any of the situations separately. However, one cannot be neglected, since each characterizes some property of the phenomenon under study, and none of them can be accepted as the only one, since it does not express all its properties. The development of a formal apparatus for solving parametric problems of assessing the effectiveness of the functioning of a communication system provides for a systemic relationship of contradictory indicators.

Based on this, an improved methodology for choosing an option for constructing an information and telecommunications system for military purposes is proposed, which differs from the existing one in that the person who makes a decision to organize communications, from certain possible options, chooses a rational one through the use of methods of analyzing hierarchies and taxonomy.

Key words: information and telecommunication system for military purposes; selection of the option for building a military information and telecommunications system; evaluation indicators.

\section{References}

1. DSTU V 3265-95 "Vyiskovy link. Terms and conditions ". 2. Viyskiy standard 01.112.001 - 2006. "Viyskiy zvyazok. Terms and conditions ". 3. Dischuk A. S. Analysis of the function of the folding system of the control system in telecommunications / A. S. Dischuk // Telecommunications and information technologies. - 2016. - №1. - S. 80-87. 4. Basarab O.K. The method of evaluating a complex imaging indicator of the effectiveness of the operational and service activity of the State borderline service of Ukraine / O.K. Basarab // Science technologies, 2013. No. 3 (19) - P. 263267. 5. Voloshko S. V. Efficiency of function of the system and connection and automation and injection into the efficiency of management of the (forces) / S. V. Voloshko, M. O. Masesov // Current information technologies in the sphere of security and defense. - 2011. - No. 3 (12). - P. 9 12. 6. Karganov V.V. Indicator for assessing the effectiveness of communication systems and their elements / V.V. Karganov, A.G. Raschesova, V.A. Kudryashov Scientific and technical statements of the St. Petersburg State Polytechnic University. Informatics. Telecommunications. Control. $-2016 / 7$. Shevchenko V. O. Systemic approach to the breaking down of methodological foundations of pre-development telecommu- nication lines of high quality / V. O. Shevchenko // Science and defense. 2004. - No. 4. - P. 42-46. 8. Elementi of the folding systems of the viscous designation / Zagorka OM, Mosov SP, Sbitnev AI, Stuzhuk PI. - K .: NAOU, 2005 --- 100s. 